27(3), 387-396

\title{
An Analysis of Factors Affecting the Variation of GDP Gap by a Decomposition Method
}

\author{
Youngjae Chang $^{a, 1}$ \\ ${ }^{a}$ Department of Information Statistics, Korea National Open University \\ (Received January 17, 2014; Revised March 9, 2014; Accepted March 17, 2014)
}

\begin{abstract}
The GDP gap (also called the output gap) is the difference between potential GDP and actual GDP. Potential GDP is the maximum sustainable output that is achieved when the resources (labor and capital) are used to capacity. Central banks pursuing price and employment stability consider the output gap as an informative variable for monetary policy since the output gap could be regarded as a proxy of demand-supply imbalances. In this paper, the GDP gap of Korea is decomposed following the filtering method in the previous research, and major factors that affect the variation of GDP gap are investigated based on the decomposed series. The analysis results by the Super Smoother algorithm used in Fox et al. (2003)and Fox and Zurlinden (2006) are found consistent with theory. Much of the variation of nominal GDP gap is explained by Total Factor Productivity(TFP) gap, which is the change of productivity due to recent technological innovation and environmental change. It is also found that variation of terms of trade significantly affects the GDP gap of Korea due to its high dependency on international trade; however, the effect of the domestic price is not negligible like other countries.
\end{abstract}

Keywords: GDP gap, GDP growth, Super Smoother.

\section{1. 서론}

\subsection{GDP갭의 의의}

$\mathrm{GDP}$ 갭(gap)이란 잠재GDP와 실제GDP의 격차로서 산출갭(Output gap)이라고도 한다. 잠재GDP는 노동, 자본 등 생산요소를 완전히 활용하여 달성할 수 있는 최대GDP라고 정의할 수 있다. 또한 인플 레이션과 연관지어보면 잠재GDP는 통상적으로 추가적인 인플레이션 압력을 유발하지 않으면서 달성 할 수 있는 최대 생산능력을 의미한다. 다른 말로 바꾸어 표현해 보면, 경제의 적정 성장수준이라고도 할 수 있다. 따라서 만약 실제GDP가 잠재GDP에 비해 높다면 GDP갭은 플러스를 나타내며, 이는 경 기과열이나 인플레이션 발생의 신호로 해석할 수 있다. 수요측면에서 물가 상승압력이 발생한다는 것 이다. 반면 GDP갭이 마이너스라면 실제GDP가 잠재GDP를 하회하는 것으로 인플레이션 압력은 낮 으나 오히려 디플레 압력이 존재하면서 경기가 위축될 가능성을 나타낸다고 할 수 있다. 통상적으로 잠 재GDP는 일정기간 중에는 그 증가율이 크게 변하지 않고 실제GDP 성장률의 기간 중 평균치와 비슷한

\footnotetext{
${ }^{1}$ Department of Information Statistics, Korean National Open University, 86 Daehak-ro, Jongno-gu, Seoul 110-791, Korea. E-mail: yjchang@knou.ac.kr
} 


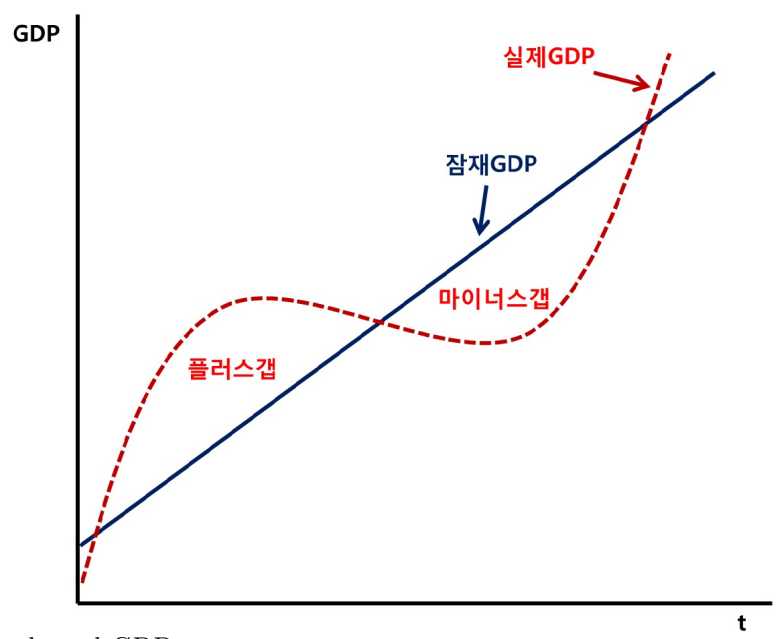

Figure 1.1. Business cycle and GDP gap

수준을 나타낸다고 볼 수 있다. 이는 Figure 1.1에서 시간의 흐름에 따라 우상향하고 있는 직선으로 표 현된다. 반면 실제 GDP 증가율은 등락을 반복하는 경기의 변동행태를 그대로 나타내므로 그림에서 점 선으로 표시된 순환변동 곡선으로 이해할 수 있다. 여기서, GDP갭은 직선에 비해 곡선이 높은 수준을 나타내는 부분에서 플러스를 나타내고 반대로 직선에 비해 곡선이 낮은 수준에 위치한 부분에서는 마이 너스를 나타내게 되고 각각이 의미하는 바는 전술한 바와 같이 물가압력 또는 디플레 압력 등으로 해석 할 수 있다. 실제 GDP가 잠재GDP로부터 얼마나 차이를 보이고 있는지를 측정하는 GDP갭률 도출식 (1.1)을 통해서도 이러한 특성을 쉽게 이해할 수 있다.

$$
\mathrm{GDP} \text { gap }=\frac{\text { 실제 GDP }- \text { 잠재GDP }}{\text { 잠재GDP }} \times 100 .
$$

결국 GDP갭은 초과수요 또는 공급애로에 대한 정보를 제공한다고 할 수 있으며 이러한 특성 때문에 물 가 및 고용안정을 추구하는 중앙은행들은 정책수행과정에서 $\mathrm{GDP}$ 갭을 중요한 정보변수로 활용하고 있 다.

\section{2. 본 연구의 특징}

본 연구에서는 우리나라의 $\mathrm{GDP}$ 갭을 그간 선행연구에서 사용되었던 필터링 방법에 의해 분해함으로써 $\mathrm{GDP}$ 갭 변동을 야기하는 주요 요인이 무엇인지 살펴보고자 한다. 그간의 선행연구를 살펴보면, Fox 등 (2003)은 뉴질랜드의 $\mathrm{GDP}$ 자료를 바탕으로 $\mathrm{GDP}$ 가 그 추세로부터의 이탈되는 정도, 즉 $\mathrm{GDP}$ 갭 의 원인을 파악하였으며 결과적으로 국내 물가(domestic prices)가 명목GDP 변동의 $60 \%$ 정도를 설 명한다고 분석하였다. Fox와 Zurlinden (2006)은 스위스의 GDP갭 자료를 바탕으로 분석한 결과, 명 목 GDP 성장을 결정하는 주요 요인들 중 국내물가가 가장 큰 영향을 미치는 반면 실질 GDP성장의 경우 에는 자본형성(capital formation)이 가장 큰 영향을 미치는 요인으로 나타난다고 주장하였다. Sherbaz 등 (2009)은 파키스탄의 GDP갭을 추정하고 그 결정요인을 분석하여 통화공급(money supply) 및 수 입(imports)이 GDP갭의 상승을 초래하는 반면 수출(exports)과 공공부문 투자(public sector investment)는 GDP갭을 줄이는 방향으로 영향을 미치고 있음을 보였다. 우리나라의 경우에는 GDP갭 자 체의 추정방법이나 불확실성 등에 관한 연구는 다수 존재하나 GDP갭을 분해하고 영향요인을 구분하 
여 분석한 연구는 거의 없는 실정이다. 따라서 본고에서는 선행연구에서 사용한 이론적 배경 및 필터링 방법을 준용하여 우리나라의 GDP갭을 분해하고 결과를 해석하는 한편 선행연구의 분석결과와도 비교 해 보기로 한다. 본고는 2 장에서 $\mathrm{GDP}$ 갭 분해의 이론적 배경에 대하여 개괄한 뒤 분해기법으로 사용 한 Super Smoother 알고리즘에 대해 살펴보았다. 3장에서는 명목GDP갭의 분해 결과를 제시하고 이 를 통해 구성요인별 특성을 비교해 보았으며 마지막으로 4 장에서는 본고의 분석결과를 간락히 정리하고 분석결과가 시사하는 바를 생각해 보았다.

\section{GDP갭의 분해}

\subsection{GDP갭 분해의 이론적 배경}

본고에서는 여러 선행연구들을 참고하여 GDP갭을 분해하여 그 의미를 해석해 보았다. Fox 등 (2003)과 Fox와 Zurilnden (2006) 등이 보인 명목GDP갭 분해의 이론적인 배경을 살펴보면 다음과 같다. 우 선 명목GDP갭을 크게 총요소생산성(total factor productivity), 국내가격(domestic price), 교역조 건(terms of trade), 노동(labor), 자본(capital) 등의 요인으로 분해해 보도록 한다. $N_{d}, N_{x}, N_{m}$ 을 각 각 국내 비교역재(domestic non-traded goods), 수출재(export goods), 수입재(import goods) 품목 수 $\left(N=N_{d}+N_{x}+N_{m}\right)$ 라고 하자. $y \equiv\left(y_{1}, y_{2}, \ldots, y_{N}\right)^{\prime}$ 가 해당 품목의 순산출(net output)을 나 타내는 벡터, $p \equiv\left(p_{1}, p_{2}, \ldots, p_{N}\right)^{\prime}>>0_{N}$ 는 해당 가격벡터, $v \equiv\left(v_{1}, v_{2}, \ldots, v_{M}\right)^{\prime}>>0_{M}$ 는 본 원 투입(primary inputs), $w \equiv\left(w_{1}, w_{2}, \ldots, w_{M}\right)^{\prime}>>0_{M}$ 는 본원 투입과 관련된 가격벡터라고 하면 $\operatorname{GDP}(Y)$ 는

$$
Y=p \cdot y=w \cdot v
$$

와 같이 각 벡터의 내적으로 표현된다. 여기서 가격벡터 및 본원투입의 '>>' 기호는 각 개별 품목의 가 격이 0이 아닌 양의 값을 가짐을 의미한다. 이러한 가정 하에서 한 국가의 GDP에 대한 두 관측치를 $Y^{a}$ 와 $Y^{b}$ 라고 하면 두 관측치의 비율 $\Gamma^{a, b}$ 는

$$
\Gamma^{a, b} \equiv \frac{Y^{b}}{Y^{a}}=\frac{\left(p^{b} \cdot y^{b}\right)}{\left(p^{a} \cdot y^{a}\right)}
$$

이 되고 이를 $a$ 와 $b$ 두 상태(states) 간의 순산출에 관한 가격지수(price index) $P^{a, b}$ 로 나누면 아래와 같이 물량지수(quantity index) $Q^{a, b}$ 를 얻게 된다 (Allen과 Diewert, 1981).

$$
Q^{a, b} \equiv \frac{\Gamma^{a, b}}{P^{a, b}}
$$

또한 $N$ 품목의 순산출이 $M$ 개의 본원 투입을 포함한다는 가정 하에 $a$ 와 $b$ 두 상태 간의 본원 투입 물량 지수 $V^{a, b}$ 와 총요소생산성 지수(Total Factor Productivity index) $R^{a, b}$ 의 관계는 다음과 같이 정의 되 고,

$$
R^{a, b} \equiv \frac{Q^{a, b}}{V^{a, b}} .
$$

식 (2.3)과 식 (2.4)로부터 다음의 관계식이 성립된다.

$$
\Gamma^{a, b}=R^{a, b} P^{a, b} V^{a, b}
$$

이상의 결과를 바탕으로 Törnqvist (1936) index를 식 (2.6) 및 식 (2.7)과 같이 정의한다. 여기서 Törnqvist index는 두 시점에서의 가치의 산술평균을 가중치로하여 기준시점 대비 현 시점의 상대적 
인 가격을 기하평균한 값으로 정의한 것이다. 이러한 절차를 거쳐 가격지수나 본원 투입 지수를 개별 순산출이나 본원 투입 Törnqvist index의 곱(식 (2.8) 및 식 $(2.9))$ 으로 표현할 수 있게된다. 여기서 $s_{n}=\left(p_{n} y_{n}\right) /(p \cdot y)$ 이며, $s_{m}=\left(w_{m} v_{m}\right) /(p \cdot y)$ 이다.

$$
\begin{aligned}
P^{a, b} & \equiv \exp \left[\sum_{n=1}^{N} \frac{1}{2}\left(s_{n}^{a}+s_{n}^{b}\right) \ln \left(\frac{p_{n}^{b}}{p_{n}^{a}}\right)\right], \\
V^{a, b} & \equiv \exp \left[\sum_{m=1}^{M} \frac{1}{2}\left(s_{m}^{a}+s_{m}^{b}\right) \ln \left(\frac{v_{m}^{b}}{v_{m}^{a}}\right)\right], \\
P^{a, b} & =\prod_{n=1}^{N} P_{n}^{a, b} \\
V^{a, b} & =\prod_{m=1}^{M} V_{m}^{a, b} .
\end{aligned}
$$

이에 따라 식 (2.5)에서 정의하였던 비율 $\Gamma^{a, b}$ 는 다음과 같이 바꾸어 쓸 수 있다.

$$
\Gamma^{a, b}=R^{a, b} \prod_{n=1}^{N} P_{n}^{a, b} \prod_{m=1}^{M} V_{m}^{a, b},
$$

여기서 식 (2.10)의 $a$ 와 $b$ 를 각각 잠재GDP(potential output or potential GDP)와 실제GDP라고 하 면 $\Gamma^{a, b}$ 는 잠재 $\mathrm{GDP}$ 대비 실제 $\mathrm{GDP}$ 로서 $\mathrm{GDP}$ 갭 측정치로 간주할 수 있으며 일정 시점 $\mathrm{t}$ 에서의 총요 소생산성은 식 $(2.11)$ 과 같게 된다.

$$
R^{t}=\frac{\left(\Gamma^{t} / P^{t}\right)}{V^{t}}
$$

이를 다시 바꾸어 식 (2.12)와 같이 정리하면 GDP갭의 분해로 해석이 가능하게 된다.

$$
\Gamma^{t}=R^{t} P^{t} V^{t}
$$

따라서 명목GDP갭은 식 (2.13)과 같이 세부적으로 분해되며 로그변환시 GDP갭이 각 요인별 갭의 합으로 구성됨을 보일 수 있게 된다. 여기서 $R^{t}$ 는 총요소생산성의 추세치로부터의 변동을 의미하며 $A^{t}, P_{E}^{t}, V_{L}^{t}, V_{K}^{t}$ 은 각각 교역조건, 국내가격, 노동투입 및 자본투입의 추세치로부터의 변동을 의미한다.

$$
\Gamma^{t}=R^{t} P^{t} V^{t}=R^{t} A^{t} P_{E}^{t} V_{L}^{t} V_{K}^{t} .
$$

결과적으로 명목 $\mathrm{GDP}$ 갭과 실질GDP갭과의 차이는 국내가격갭과 교역조건갭으로 설명할 수 있는 것이 다. 이는 명목성장률이 실질성장률과 물가상승률의 합으로 근사되는 성장률의 관점뿐만 아니라 갭들 간 에도 유사한 관계성이 있다는 주장을 뒷받침 하는 결과라 하겠다.

\subsection{GDP갭 분해 알고리즘}

본고에서는 기존의 선행연구와의 비교를 위해 Fox 등 (2003)과 Fox와 Zurilnden (2006) 등에서 쓰였던 Super Smoother 알고리즘을 사용하였다. Super Smoother 알고리즘은 Friedman (1984)에 의해 제안 된 것으로 $\mathrm{k}$ 근접 이웃 영역(k-nearest neighbors) 내에 위치한 관측치와 데이터 포인트와의 거리를 기 반으로 부드러운 함수(smooth function)을 추정하는 과정이다. Super Smoother 알고리즘의 추정 절 차를 간략하게 살펴보면 다음과 같다. 
1. 임의의 데이터 포인트 $R^{0}$ 를 중심으로 $\mathrm{k}$ 근접 이웃 영역(k-nearest neighbors)을 span으로 정의하고 동 $\operatorname{span}$ 내에 위치한 관측치들을 $R^{0}$ 의 이웃, $N\left(R^{0}\right)$ 로 정의한다. 여기서 적정 $\operatorname{span}$ 을 찾는 방법으 로는 cross-validation 기준 (Schmidt, 1971; Stone, 1974)을 사용한다.

2. $N\left(R^{0}\right)$ 내의 관측치와 $R^{0}$ 간의 최대거리를 아래와 같이 산출한다.

$$
\Delta R^{0}=\max _{N\left(R^{0}\right)}\left|R^{0}-R^{i}\right| \text {. }
$$

3. $N\left(R^{0}\right)$ 내의 각각의 관측치에 대해서 가중치를 부여하기 위해 아래와 같은 가중함수(weight function)를 설정한다.

$$
\begin{aligned}
& W\left(\frac{\left|R^{0}-R^{i}\right|}{\Delta R^{0}}\right) \\
& \text { 단, } W(u)= \begin{cases}\left(1-u^{3}\right)^{3}, & \text { for } 0 \leq u<1, \\
0, & \text { 나머지 구간. }\end{cases}
\end{aligned}
$$

4. 위에서 구한 가중치를 이용하여 $R^{0}$ 를 종속변수로, $N\left(R^{0}\right)$ 의 각 관측치들을 독립변수로 하는 가중최 소자승(weighted least squares) 모형을 설정하고 이 모형에 의한 추정값을 $S^{0}$ 로 정의한다.

5. 이상의 과정을 모든 관측치에 대해서 반복하여 최종적으로 smooth function $S$ 를 추정한다.

프로그램 언어 R의 stats 패키지 내에서는 동 알고리즘을 구현한 함수 supsmu가 제공되고 있다.

\section{3. 명목GDP갭의 분해를 통한 구성요인별 특성 비교}

\section{1. 분석대상 기간 및 자료}

명목GDP갭 분해를 실행하고 특성을 분석하기 위해 앞서 살펴본 이론에 따라 각 구성요인들의 추세를 추출하여 순환변동치를 구하여 해당 항목의 갭으로 정의하였다. 각 구성요인은 교역조건, 국내가격(소 비자물가 상승률), 노동투입, 자본투입 등으로 교역조건 및 국내가격은 한국은행 ECOS에 수록된 데이 터를 이용하였다. 노동투입과 자본투입은 통계청 KOSIS의 인구추계 및 국가자산통계 추계 결과를 바 탕으로 추정하였다. 또한, 명목 GDP갭과 각 구성요인 갭과의 잔차를 총요소생산성갭으로 정의하여 정 합성을 유지하고자 하였다. 분석대상 기간은 $1990.1 / 4$ 분기 $2012.4 / 4$ 분기이며 추세추출을 위해서는 앞 서 살펴본 Super Smoother 알고리즘을 이용하였다.

\section{2. 명목GDP갭 구성요인 분석}

우리나라의 명목GDP갭을 분해해 본 결과 선행연구 결과 및 이론적인 설명에 부합하는 것으로 나타났 으며 몇 가지 특징도 파악할 수 있었다. Figure 3.1에서 보듯이 명목GDP갭률 변동의 상당부분은 잔 차인 총요소생산성과 교역조건갭으로 설명됨을 알 수 있다. 이는 최근들어 노동 및 자본 등 전통적인 생산함수 접근법의 $\mathrm{GDP}$ 구성 요소에 비해 급격한 기술변화 및 환경변화 등 생산성 변화가 GDP변동 에 큰 영향을 주고 있음을 의미한다. 또한 대외 의존도가 높은 우리 경제의 특성상 교역조건의 변동도 상대적으로 명목GDP 움직임에 큰 영향을 주고 있다고 볼 수 있다. 다만, 경기의 급변동으로 인한 실 제 $\mathrm{GDP}$ 와 추세 $\mathrm{GDP}$ 간의 본질적인 괴리, 추계 기법에 내재한 태생적인 오차 문제 등으로 잔차 폭이 확 대되어 총요소생산성이 실제보다 크게 추정되었을 가능성도 있다. 


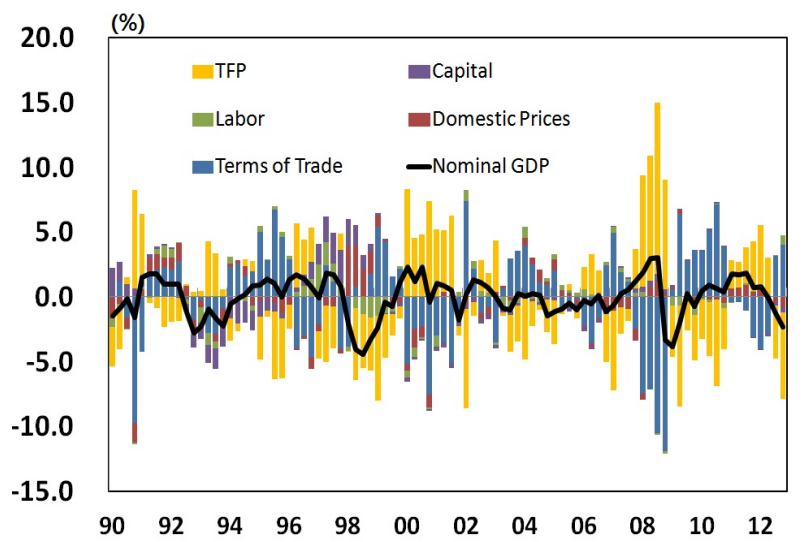

Figure 3.1. GDP gap and its components

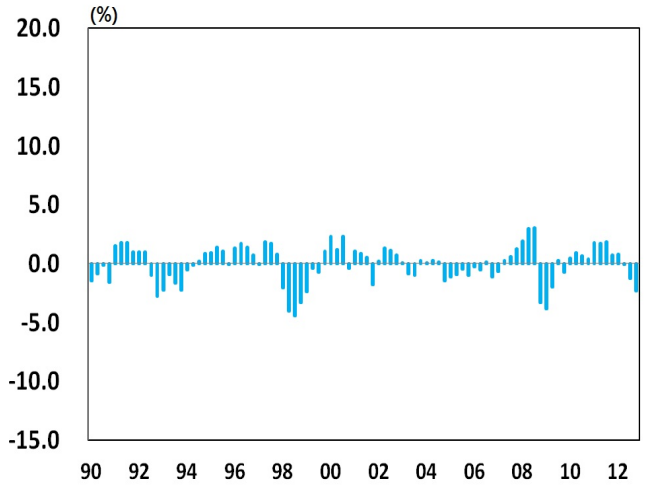

(a) Nominal GDP gap

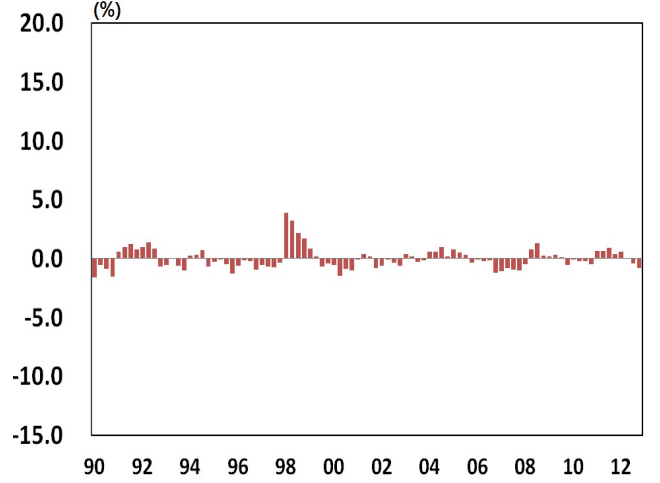

(b) Domestic Prices gap

Figure 3.2. Nominal GDP gap and Domestic Prices gap

보다 구체적으로 개별 요인의 특성을 살펴보기 위해 각 요인별로 갭률을 분리하여 제시하였다. 교역 조건이나 총요소생산성을 제외한 개별 요인들이 상대적으로 변동 폭이 작게 나타나고 있지만 그 추이 를 통해서는 몇 가지 특징적인 점을 파악할 수 있다. 첫째로, Figure 3.2과 같이 명목GDP갭률과 물 가상승률갭률 간에 상보적인 관계가 나타난다는 것이다. 이는 실제 $\mathrm{GDP}$ 에 가격요인을 추가적으로 고 려하여 명목 $\mathrm{GDP}$ 를 산출할 수 있다는 점에서 이론과 부합하는 결과라고 할 수 있다. 두 지표 간 교 차상관관계를 구해보면 명목 $\mathrm{GDP}$ 갭률이 물가상승률 갭률과 $1 \sim 2$ 분기 시차에서 가장 큰 음의 상관관 계 $(-0.45 \sim-0.53)$ 를 나타낸다는 점은 이를 뒷받침한다 할 수 있겠다.

또한 Figure 3.3 으로부터 교역조건갭률의 변동폭이 매우 큰 것을 알 수 있다. 앞서 살펴 본 국내 물가 변동폭이 상대적으로 작게 추정된 것은 대외 의존도가 높은 우리 경제의 특성상 교역조건갭률의 변동폭 이 매우 크게 추정된 데 기인한다고 볼 수 있다. 이 교역조건갭률을 제외하면, 국내 물가갭률의 영향력 이 전통적인 생산함수접근법에 의해 산출되는 요소들, 즉 노동이나 자본의 변동에 비해 여전히 큰 것으 로 나타났으므로 다른 나라들을 분석한 여러 선행연구 결과와 유사한 것으로 볼 수 있다. 교역조건갭률 의 추이를 보면 2011 년이래 마이너스를 기록하다가 2012 년 $3 / 4$ 분기부터 플러스로 전환하여 이후 개선 의 여지를 보여주고 있다. 이런 점을 주목해 본다면 대외 의존도가 크게 낮아지지 않고 있는 현 우리 경 


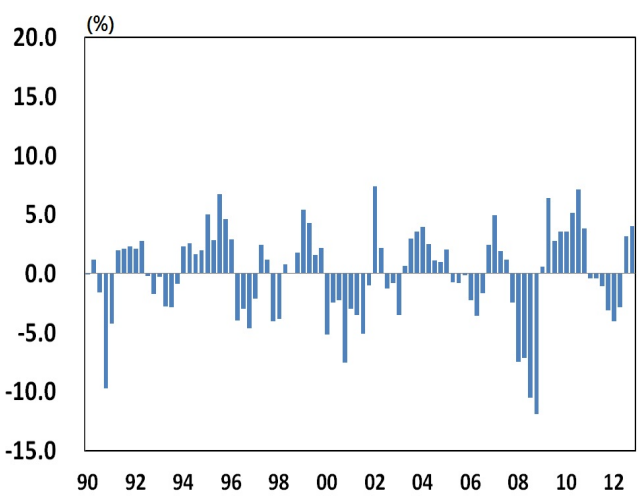

(a) Terms of Trade gap

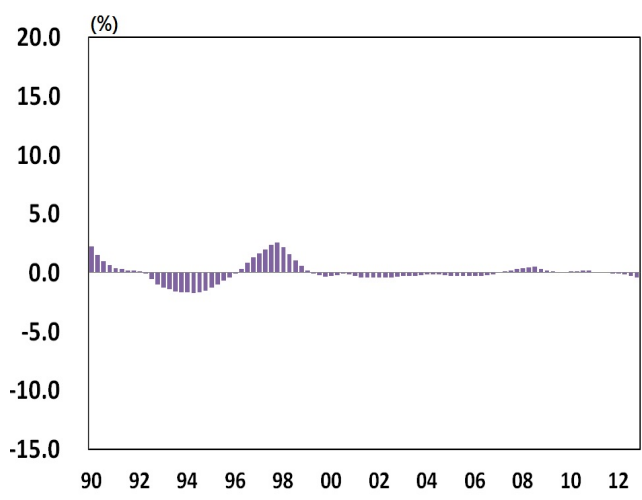

(b) Capital gap

Figure 3.3. Terms of Trade gap and Capital gap

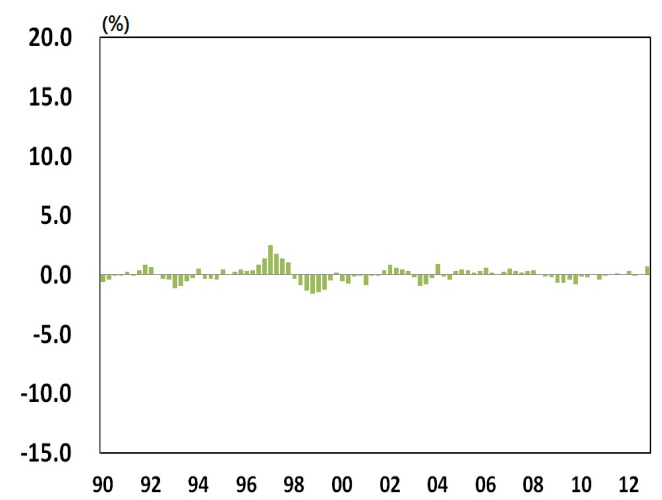

(a) Labor gap

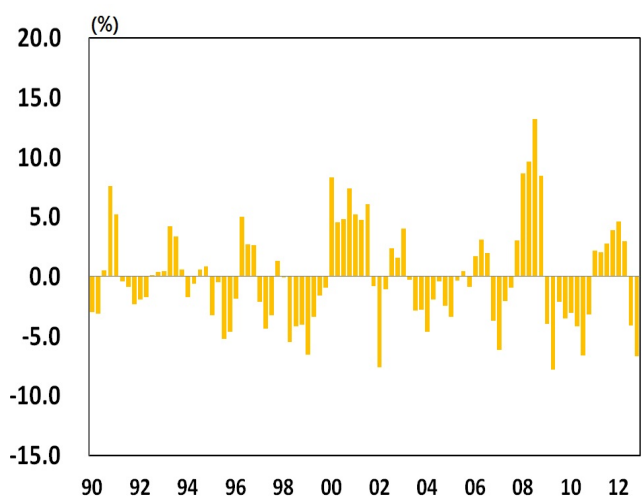

(b) Total Factor Productivity gap

Figure 3.4. Labor gap and Total Factor Productivity gap

제의 구조상, 수출 주도의 성장이 어느정도 지속되면서 내수에 의해서보다는 외수에 의해서 물가변동에 미치는 영향이 커질 가능성을 의미한다고도 할 수 있다. 이러한 대외 여건의 영향력 변화는 이승용 등 (2007)에서 검토했던 글로벌 경제의 국내 물가 영향력에 대한 평가를 새롭게 할 필요성을 부각시키고 있 다고 하겠다. 한편, 자본갭의 변동폭은 상당히 축소된 것으로 보아 실제 설비투자(플로우)의 급등락에 도 불구하고 자본스톡의 변동은 크지 않다는 점을 알 수 있다. 달리 표현하면 경기의 급변동에 따라 설 비투자 자체의 변동성은 크게 나타나지만, 자본축적의 변동성은 상대적으로 작게 평가되면서 자본 축적 이 꾸준히 지속되고 있는 것으로 해석할 수 있다. 다만, 이상의 두 지표 모두 명목GDP갭률의 교차상관 관계는 다른 지표에 비해 뚜렷하지 않거나 장기 시차를 두고 음의 값을 나타내는 것으로 분석되었는데 이는 여타 지표와 상이한 변동패턴에 기인한다고 할 수 있다.

마지막으로 노동갭률의 경우 자본갭률과 마찬가지로 변동폭은 크지 않지만 경기에 매우 민감하게 반응 하는 것으로 보인다. 즉, 1998 년의 외환위기 직후라든지, 2003 년 카드사태 시기, 그리고 2009년을 전후 한 글로벌 금융위기 시의 고용의 위축이 뚜렷하게 드러나는 반면, 경기호황기에서는 몇 분기 연속 개선 되는 모습을 보이는 것이다. 한편, 총요소생산성갭률은 매우 큰 폭의 변동을 나타내고 있다. 이는 총요 
소생산성 자체가 생산함수 접근법에 의하여 잔차로 계산되는 태생적인 부분도 영향을 미친다고 할 수 있 지만, 장기간에 걸쳐 양의 값을 나타낸 부분을 보면 급격한 기술혁신이라든지 경제환경 변동으로 생산성 이 향상되었다고 판단할 수 있다. 명목 GDP 갭률과 노동갭률, 명목 GDP 갭률과 총요소생산성갭률 간의 교차 상관계수가 동차내지는 1 분기 정도 시차에서 각각 $0.42 \sim 0.45,0.39 \sim 0.48$ 정도로 계산되어 이러한 두 지표 변동성의 특징을 확인해 준다. 노동갭률과 총요소생산성갭률의 추이는 Figure 3.4 에 잘 나타나 있다.

\section{4. 결론}

본 연구에서는 선행연구를 따라 Super Smoother 알고리즘을 이용하여 우리나라의 GDP 갭을 분해하고 그 구성요인별 특성을 비교하여 보았다. GDP갭률과 물가상승률갭률 간에 상보적인 모습을 보이면서 이론과 부합하는 것으로 나타났다. 명목 GDP를 분해한 결과에 바탕을 둔 분석이므로 GDP갭률이 물가 압력과 밀접한 관계가 있음을 또한 간접적으로 입증하는 결과라고도 해석할 수 있다. 특히 총요소생산 성의 변동폭이 매우 크게 나타났는데 급격한 기술변화 및 환경변화 등 생산성 변화를 의미한다고 볼 수 있다. 다만, 총요소생산성 계열 자체가 생산함수 접근법에서는 잔차로 계산되면서 나타하는 착시효과일 수도 있다는 점에 유의하여야 하겠다. 외환위기와 금융위기 등 급격한 변동기를 겪은 우리경제의 특수 성에 기인하여 다소 과다 계상되어 나타났을 가능성도 배제하지는 못한다. 또한 대외 의존도가 높은 우 리 경제의 구조상 교역조건갭률의 변동폭이 매우 크게 나타나면서 국내 물가 변동폭이 상대적으로 작게 추정되었다. 이는 우리 경제에 미치는 물가압력을 평가할 때, 대외 여건도 중시하여 판단해야 한다는 점 을 시사한다. 이렇듯 GDP갭 분해를 통해 여러 가지 의미 있는 경제적 해석이 가능하지만 분해 대상인 $\mathrm{GDP}$ 갭 자체가 직접적인 관측이 불가능하다는 제약이 있음에 유의해야 한다. 박양수 등 (2013)에서도 지적하였듯이 시계열 접근법, 생산함수 접근법, 구조적 모형 접근법 등 GDP갭 추정방법별 추정치의 오 차와 추정방식에 따른 불확실성이 존재함을 감안한다면 분석 결과의 해석에 보다 신중해야 한다는 것이 다. 또한 일정 주기로 분석대상 자료로 사용된 국가자산통계 등이 개정(revision)되면서 시계열 변화에 따른 추세 및 순환변동치도 다소 변화할 수 있음도 고려하여야 한다. 특히 각 구성요인의 부호 전환 시 점 등은 가변적이라는 점을 충분히 인식하여 해석에 유의해야 하겠다. 또 한 가지 연구의 한계점으로 꼽 을 수 있는 것은 자료의 부족이다. 가용한 자료를 최대한 확보하여 분석하였음에도 불구하고 필터링 기 법의 적용상 짧은 시계열로 인해 초래되는 문제점이 존재한다. 따라서, 의미있는 분석결과를 얻어 정책 에 반영하기 위해서는 향후 지속적인 관찰과 추적연구를 통해 추정의 불확실성을 줄이려는 노력도 필요 하다 하겠다. 더불어 우리나라의 GDP갭률에 교역조건 등 대외 여건이 큰 영향을 주는 것으로 나타난 점에 비추어 글로벌 경기 변동이 국내물가에 미치는 압력의 분석 등 국제적인 시각에서의 연구로 확장할 필요도 있다 하겠다.

\section{References}

Allen, R. C. and Diewert, W. E. (1981). Direct versus Implicit Superlative Index Number Formulae, The Review of Economics and Statistics, 63, 430-435.

and overseas investment using a regression tree, The Korean Journal of Applied Statistics, 24, 455-464.

Fox, K. J., Kohli, U. and Warren, R. S. (2003). Sources of growth and output gaps in New Zealand: New methods and evidence, New Zealand Economic Papers, 37, 67-92.

Fox, K. J. and Zurlinden, M. (2006). On understanding sources of growth and output. Gaps for Switzerland, Swiss National Bank Working Papers, 2006-10.

Friedman, J. H. (1984). A variable span scatterplot smoother, Laboratory for Computational Statistics, Stanford University Technical Report, No. 5. 
Lee, S. and Han, M. (2007). The Influence of GDP Gap on Inflation, Monthly Bulletin, The Bank of Korea, November 2007, 23-52.

Park, Y., Chang, Y., Koo, J. and Kim, H. (2013). Uncertainty of GDP gap estimation and Monetary Policy, Monthly Bulletin, The Bank of Korea, April 2013, 14-33.

Schmidt, F. L. (1971). The relative efficiency of regression and simple unit predictor weights in applied differential psychology, Educational and Psychological Measurement, 31, 699-714.

Sherbaz, S., Amjad, F. and Khan, N. Z. (2009). Output gap and its determinants: Evidence from Pakistan (1964-05), Journal of Economic Cooperation and Development, 30, 75-98.

Stone, M. (1974). Cross-validatory choice and assessment of statistical predictions, Journal of the Royal Statistical Society: Series B, 36, 111-147.

Törnqvist, L. (1936). The Bank of Finland's Consumption Price Index, Bank of Finland Monthly Bulletin, 10, 1-8. 


\title{
$\mathrm{GDP}$ 갭 분해기법을 이용한 변동요인 분석
}

\author{
장영재 ${ }^{a, 1}$ \\ ${ }^{a}$ 한국방송통신대학교 정보통계학과
}

(2014년 1월 17일 접수, 2014년 3월 9일 수정, 2014년 3월 17일 채택)

\section{요 약}

$\mathrm{GDP}$ 갭(gap)이란 잠재GDP와 실제 GDP의 격차로서 산출갭(Output gap)이라고도 한다. 잠재GDP는 노동, 자본 등 생산요소를 완전히 활용하여 달성할 수 있는 최대GDP라고 정의할 수 있다. GDP갭은 수요-공급간 불균형을 의 미한다고 할 수 있으며 이러한 특성 때문에 물가 및 고용안정을 추구하는 중앙은행들은 정책수행과정에서 GDP갭 을 중요한 정보변수로 활용하고 있다. 본 연구에서는 우리나라의 GDP갭을 그간 선행연구에서 사용하였던 필터링 방법에 의해 분해함으로써 GDP갭 변동을 야기하는 주요 요인이 무엇인지 살펴보았다. Fox 등 (2003)와 Fox와 Zurlinden (2006)에서 사용되었던 Super Smoother 알고리즘을 이용하여 우리나라의 명목GDP갭을 분해해 본 결 과 이론적인 설명에 부합하는 것으로 나타났다. 명목GDP갭률 변동의 상당부분은 잔차인 총요소생산성으로 설명됨 을 알 수 있었는데, 이는 최근들어 급격한 기술변화 및 환경변화 등 생산성 변화가 GDP변동에 큰 영향을 주고 있음 을 의미한다. 다른 나라의 경우와 마찬가지로 국내물가의 영향력도 높은 것으로 나타났지만 대외 의존도가 높은 우 리 경제의 특성상 교역조건의 변동 역시 상대적으로 명목 $\mathrm{GDP}$ 움직임에 큰 영향을 주고 있는 것으로 분석되었다.

주요용어: GDP갭, GDP 성장, Super Smoother. 